\title{
Article \\ Influence of Traditional and Solar Reflective Coatings on the Heat Transfer of Building Roofs in Mexico
}

\author{
Iván Hernández-Pérez
}

check for

updates

Citation: Hernández-Pérez, I.

Influence of Traditional and Solar Reflective Coatings on the Heat Transfer of Building Roofs in Mexico. Appl. Sci. 2021, 11, 3263. https:// doi.org/10.3390/app11073263

Academic Editor: Tiziana Poli

Received: 28 February 2021

Accepted: 2 April 2021

Published: 6 April 2021

Publisher's Note: MDPI stays neutral with regard to jurisdictional claims in published maps and institutional affiliations.

Copyright: (c) 2021 by the authors. Licensee MDPI, Basel, Switzerland. This article is an open access article distributed under the terms and conditions of the Creative Commons Attribution (CC BY) license (https:/ / creativecommons.org/licenses/by/ $4.0 /)$.
División Académica de Ingeniería y Arquitectura (DAIA-UJAT), Universidad Juárez Autónoma de Tabasco, Carretera Cunduacán-Jalpa de Méndez km. 1, Cunduacán, Tabasco CP 86690, Mexico; ivan.hernandezp@ujat.mx; Tel.: +52-777-227-4111

\begin{abstract}
Building roofs are sources of unwanted heat for buildings situated in zones with a warm climate. Thus, reflective coatings have emerged as an alternative to reject a fraction of the solar energy received by roofs. In this research, the thermal behavior of concrete slab roofs with traditional and solar reflective coatings was simulated using a computational tool. The studied slab configurations belong to two groups, non-insulated and insulated roofs. In the second group, the thermal insulation thickness complies with the value recommended by a national building energy standard. Weather data from four cities in Mexico with a warm climate were used as boundary conditions for the exterior surface of the roofs. The computational tool consisted of a numerical model based on the finite volume method, which was validated with experimental data. A series of comparative simulations was developed, taking a gray roof as the control case. The results demonstrated that white roofs without insulation had an exterior surface temperature between 11 and $16{ }^{\circ} \mathrm{C}$ lower than the gray roof without insulation. Thus, the daily heat gain of these white roofs was reduced by a factor ranging between 41 and 54\%. On the other hand, white roofs with insulation reduced the exterior surface temperature between 17 and $21^{\circ} \mathrm{C}$ compared to the gray roof with insulation. This temperature reduction caused insulated white roofs to have a daily heat gain between 37 and $56 \%$ smaller than the control case. Another contribution of this research is the assessment of two retrofitting techniques when they are applied at once. In other words, a comparison between a non-insulated gray roof and an insulated white roof revealed that the latter roof had a daily heat gain up to 6.4-times smaller than the first.
\end{abstract}

Keywords: solar reflective coatings; heat transfer; daily heat gains; cool roofs

\section{Introduction}

The buildings sector used 36\% of the total final energy around the world and had $39 \%$ of the energy-related $\mathrm{CO}_{2}$ emissions in 2018 [1]. Because the population is expected to increase by 2.5 billion people by 2050 , the energy use in the building sector is set to rise sharply. In warm locations, the energy consumption from air conditioners is high due to the heat flow received by buildings situated in these zones. The building envelope plays a vital role in the thermal interaction between the outdoor and indoor environments. Thus, it is important to minimize the energy gain from the building envelope to avoid the excessive use of electricity for comfort purposes.

Today, several technologies are available for building energy retrofitting. There are advanced facades [2], highly insulated windows [3], high insulation levels for roofs and walls [4], reflective coatings [5], phase change materials [6], and well-sealed structures [7], to mention a few. In particular, reflective surfaces are becoming popular for two main reasons. First, the most direct way to reduce the incident solar energy is to reflect it. When new, solar reflective coatings can reflect to the sky up to $90 \%$ of the solar energy received by a surface. The second reason is that applying reflective coatings to opaque building components is probably the most simple passive measure because most of these coatings 
can be installed in the same way as ordinary paint [8]. These coatings are usually used on building roofs because these components are subject to solar radiation for more hours than other building envelope components [9]. Therefore, when a roof is retrofitted with a reflective coating, it is known as a cool roof.

Several researchers around the world have studied the benefits that cool roofs can bring to buildings in different types of climates using a number of approaches. Several experimental studies are available in the literature. For instance, Pisello and Cotana [10] performed a two-year monitoring campaign to test cool roofs in a residential building located in Italy. The results showed that the cool roof solution reduced the peak temperature of the air in the attic by around $5^{\circ} \mathrm{C}$. Further, the cool roof provided an overall year-round energy savings that corresponded to $14 \mathrm{kWh} / \mathrm{m}^{2}$ per year. In China, Quin et al. [11] used a building cell to test different samples of concrete tiles with different solar reflectance. The authors performed a series of experiments and found that the tiles with a reflective coating reached lower interior surface temperatures than the control tile. Moreover, an additional 2-6 ${ }^{\circ} \mathrm{C}$ cooler temperature around the noon time was achieved by installing at the bottom of the tile a low-emissivity sheathing. Hernández-Pérez et al. [12] evaluated several building roofs with different coatings using two outdoor test cells located in Cuernavaca, Mexico. They showed that in summer, the white roof was $29^{\circ} \mathrm{C}$ cooler than the black roof and just $1.5^{\circ} \mathrm{C}$ warmer than the ambient air. Further, the average daily energy gain of the white roof was $73 \%$ less than the black roof.

Other studies aiming to investigate the year-round energy savings from cool roofs by using building energy simulation tools are available. Algarni [13] studied the influence of solar reflective roofs on the energy consumption of residential buildings of Saudi Arabia. The author used eQuest building simulation software to perform simulations of a building prototype using weather data of 13 major cities of this country. The researcher found that a reflective roof reduced the annual energy consumption required for building cooling by between 110.3 and $181.9 \mathrm{kWh} / \mathrm{m}^{2}$. The maximum increase in annual energy consumption due to winter heating was only $4.4 \mathrm{kWh} / \mathrm{m}^{2}$. Piselli et al. [14] assessed the effectiveness of cool roofs with optimal insulation levels in different weather conditions worldwide. The authors coupled a dynamic energy simulation tool with an optimization technique to find the best-combined building roof thermal insulation and solar reflectance and minimize the annual energy consumption. The results showed that a high value of solar reflectance reduced the annual energy consumption for most of the analyzed climate zones. Thus, they concluded that the optimal roof configuration must have high solar reflectance and no/a low insulation level. Dominguez-Delgado et al. [15] developed an energy and economic life cycle assessment of cool roofs applied to residential buildings in Southern Spain. The simulations demonstrated that the cool roof decreased the annual energy consumption. The maximum decrease found by the authors was $32 \%$, and it was obtained when a roof with a solar reflectance of 0.1 was retrofitted with a reflective coating with a solar reflectance of 0.9 . The LCA analysis reported that savings were $18.33 € / \mathrm{m}^{2}$, and the payback period was around thee years.

Some researchers have used validated models to predict the benefits of cool roofs. For instance, Tong et al. [16] studied the thermal behavior of ventilated and non-ventilated roofs during a typical day in Singapore. The authors conducted experiments to validate the concrete roof models. Compared with the roofs with a solar reflectance of 0.1, each 0.1 increase in reflectance reduced the daytime heat gain by $11 \%$ on the ventilated roofs and the non-ventilated roofs. The reflective coatings application reduced the daily heat gain by 234 and $135 \mathrm{Wh} / \mathrm{m}^{2}$ in the ventilated and non-ventilated roofs, respectively. Further, they indicated that compared to non-ventilated roofs (both reflective and non-reflective), the individual use of ventilation and $2.5 \mathrm{~cm}$ of expanded polystyrene (EPS) reduced the heat gain by 42 and $68 \%$, respectively. Zingre et al. [17] developed a model to study heat transfer in roofs. They used a spectral approximation method to solve the unsteady one-dimensional heat conduction equation. Furthermore, the model was validated using experimental data obtained from measurements made in two identical apartments with 
concrete roofs located in Singapore. Model predictions showed that on a sunny day, the reflective coating reduced the maximum roof temperature, indoor air temperature, and daytime heat gain by $14.1^{\circ} \mathrm{C}, 2.4^{\circ} \mathrm{C}$, and $0.66 \mathrm{kWh} / \mathrm{m}^{2}(54 \%)$, respectively.

As shown in the literature review, reflective or cool roofs have brought a series of benefits to the buildings in which they are installed. Thus, it is essential to understand how a cool roof behaves in a particular area. For this purpose, it is necessary to have tools capable of predicting the thermal behavior of a cool roof before its installation to determine if it is feasible from an energy point of view. This work presents the development of a computational tool for modeling the heat transfer of concrete slab-type roofs with traditional and solar reflective coatings. This tool is then used to estimate the temperature reductions and, consequently, the ability of reflective roofs to modulate the heat gains by implementing this technology in buildings situated in four different warm climates in Mexico.

\section{Physical Model}

Figure 1 shows the physical model of the roof, which is a concrete slab with traditional or solar reflective coating. Two configurations were considered: (a) a single roof with a thickness of $10 \mathrm{~cm}$ and (b) an insulated roof with a thickness of $13 \mathrm{~cm}$. The insulated roof was made of concrete and polystyrene, and a thin plaster layer of concrete protected the polystyrene because it should not be exposed to solar radiation. The polystyrene had a thickness equal to $2.5 \mathrm{~cm}$, and the plaster layer had a thickness of $0.5 \mathrm{~cm}$. The width of the roof $(W)$ was considered $1 \mathrm{~m}$. Both configurations were studied with traditional and solar reflective coatings. The thickness of the coatings was considered negligible. The materials of both roof configurations were considered homogeneous. The solar absorptance and thermal emissivity of the roofs were also regarded as constant. Further, it was considered that the side surfaces of the two roof configurations were adiabatic. Finally, it was supposed that solar radiation had a normal incidence on the roof and that this was a gray body that only absorbed the incident solar radiation.

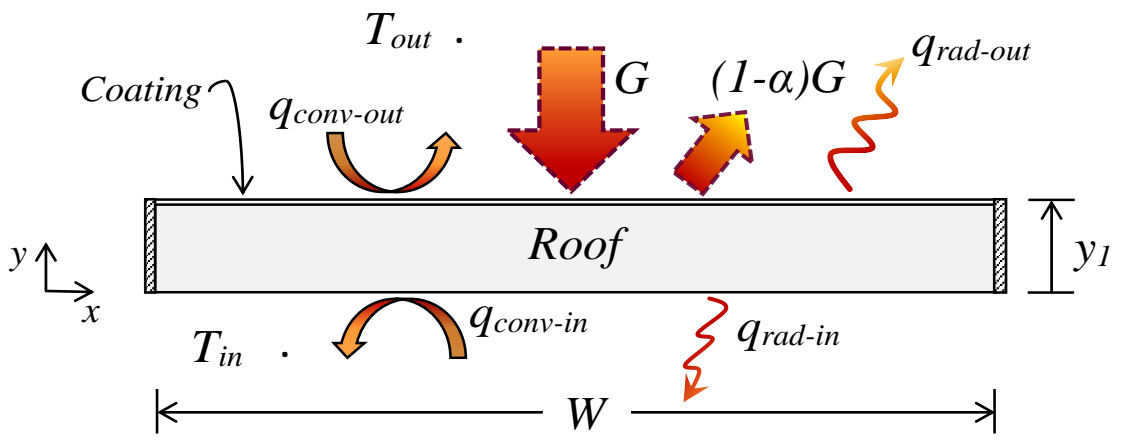

(a)

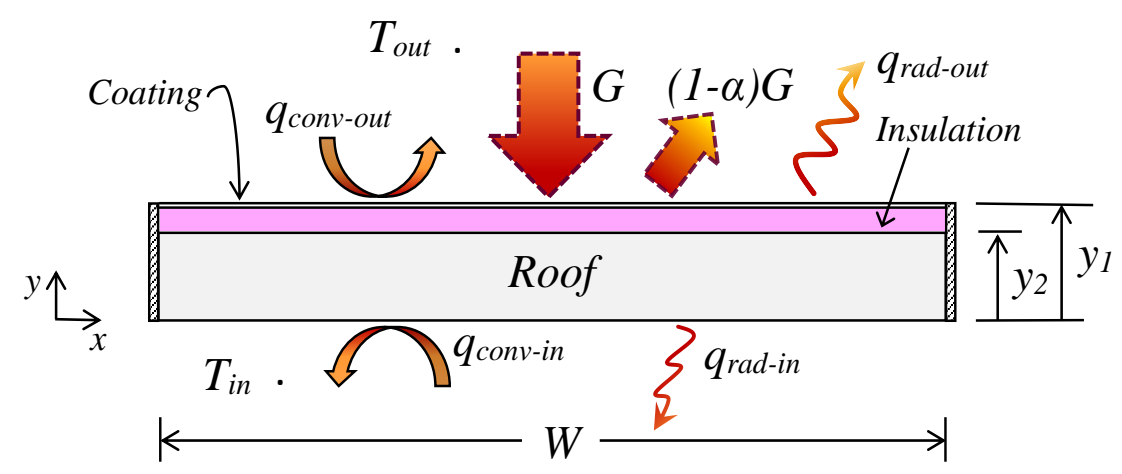

(b)

Figure 1. Physical model. (a) Single roof; (b) insulated roof. 


\section{Mathematical Model}

The partial differential equation for transient heat conduction of a two-dimensional solid is [18]:

$$
\frac{\partial\left(\rho c_{p} T\right)}{\partial t}=\frac{\partial}{\partial x}\left(\lambda \frac{\partial T}{\partial x}\right)+\frac{\partial}{\partial y}\left(\lambda \frac{\partial T}{\partial y}\right)
$$

where $\lambda$ is the thermal conductivity, $\rho$ is the density, and $c_{p}$ is the specific heat. The boundary conditions used to solve in the physical model were as follows: The exterior surface $\left(y=y_{1}\right)$ is in contact with the outdoor environment or environmental conditions of different cities of Mexico. Therefore, the roof has convective and radiative exchange with the surroundings. The lateral surfaces are thermally insulated $(x=0$ and $x=W)$, and the interior surface $(y=0)$ also exchanges heat by convection and radiation with the indoor environment. Mathematically, the boundary conditions can be expressed as:

$$
\begin{aligned}
-\lambda \frac{\partial T}{\partial y} & =\alpha G+h_{\text {out }}\left(T-T_{\text {out }}\right)+\sigma \varepsilon\left(T^{4}-T_{\text {sky }}^{4}\right) \text { for } y=y_{1}, \quad 0 \leq x \leq W \\
-\lambda \frac{\partial T}{\partial y} & =h_{\text {in }}\left(T-T_{\text {in }}\right) \text { for } y=0, \quad 0 \leq x \leq W \\
\frac{\partial T}{\partial x} & =0 \text { for } x=0, \quad 0<y<y_{1} \\
\frac{\partial T}{\partial x} & =0 \text { for } x=W, \quad 0<y<y_{1}
\end{aligned}
$$

In Equation (2), $G$ is the solar radiation received by the roof, $\alpha$ is the solar absorptance of the coating, $\varepsilon$ is the thermal emittance, and $\sigma$ is the Stefan-Boltzmann constant. The beam-solar radiation received by roofs has different angles during the day. The solar radiation data used for the simulations were obtained from measurements performed using weather stations, and these stations used pyranometers for measuring total (beam plus diffuse) radiation over a horizontal surface. The detectors of the pyranometers had a response that did not depend on radiation wavelength over the solar spectrum. Further, these devices had a response independent of the angle of incidence of solar radiation. Thus, it can be supposed that the roofs received total radiation in a perpendicular direction. To calculate the outdoor convective heat transfer coefficient $\left(h_{\text {out }}\right)$ in Equation (2), the following empirical correlation was used [19]:

$$
h_{\text {out }}=2.8+3.0 v
$$

where $v$ is the wind speed in $\mathrm{m} / \mathrm{s}$ and $h_{\text {out }}$ is the outdoor convective heat transfer coefficient in $\mathrm{W} / \mathrm{m}^{2} \mathrm{~K}$. The value of $T_{\text {sky }}$ is calculated with the following expression [19]:

$$
T_{\text {sky }}=0.0552 T_{\text {out }}^{1.5}
$$

In Equation (7), $T_{\text {out }}$ is the outdoor air temperature, and both temperatures $T_{\text {sky }}$ and $T_{\text {out }}$ are expressed in $\mathrm{K}$. The heat transfer coefficient in the interior environment $h_{\text {in }}$ in Equation (3), which considers both convection and thermal radiation, is equal to $6.13 \mathrm{~W} / \mathrm{m}^{2}$ when the heat flux heat goes to the indoor air and $9.26 \mathrm{~W} / \mathrm{m}^{2} \mathrm{~K}$ when the heat flux goes from the indoor air to the interior surface [20]. For the roof configuration (b) of Figure 1, due to the different materials involved and the thermophysical properties' changes across the interface between concrete and thermal insulation, the harmonic mean was used to calculate these properties in the interface. Furthermore, perfect contact between both materials was considered, such that heat flux through the interface was the same for the materials involved. The properties of the concrete used for the simulations were $\rho=2400 \mathrm{~kg} / \mathrm{m}^{3}$, $c_{p}=1080 \mathrm{~J} /(\mathrm{kg} \cdot \mathrm{K})$, and $\lambda=1.8 \mathrm{~W} /(\mathrm{m} \cdot \mathrm{K})$. On the other hand, the properties of the insulation were $\rho=28 \mathrm{~kg} / \mathrm{m}^{3}, c_{p}=1800 \mathrm{~J} /(\mathrm{kg} \cdot \mathrm{K})$, and $\lambda=0.033 \mathrm{~W} /(\mathrm{m} \cdot \mathrm{K})$. 


\section{Solution Methodology for the Roof Model}

This section present the methodology followed to numerically solve the heat conduction Equation (1). The following steps were developed:

- Generation of the computational mesh.

- Discretization of the mathematical model.

- Solution of the system of algebraic equations.

The discretization technique used in this work was the finite volume method (FVM), and the following subsections describe each of these steps.

\subsection{Generation of the Computational Mesh}

This step consisted of dividing the domain into small control volumes where the nodes were situated, and the value of the temperature $T(x, y)$ was determined. In this analysis, the main node $P$ was located in the center of the control volume (Figure 2), so that the its interface (point $w, e, n$, and $s$ ) was at the middle from one node to another.
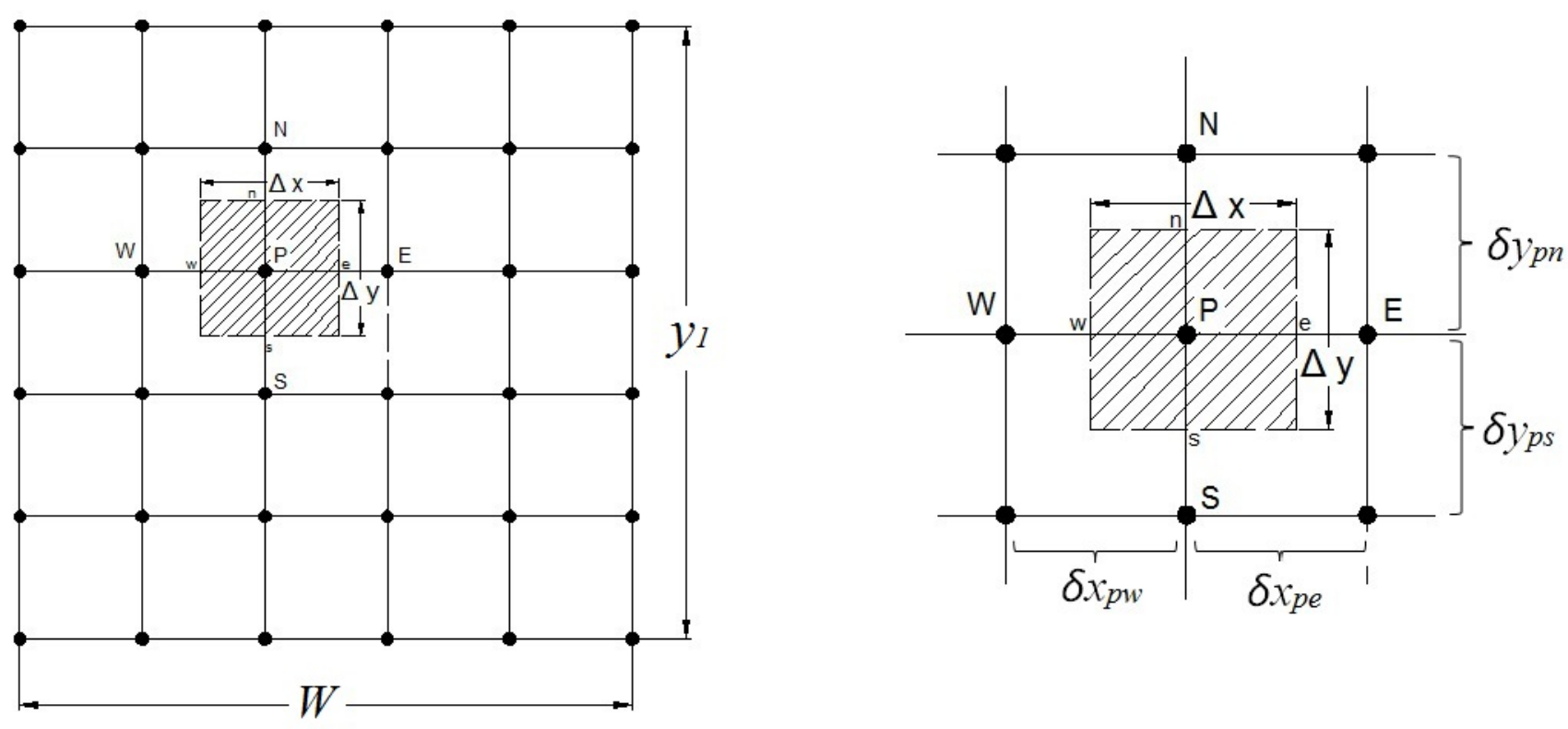

Figure 2. A control volume in the computational mesh.

Equation (8) describes the distribution of the nodes in the mesh in the direction of $x$ :

$$
x(i)=\frac{W}{N_{x}-1}(i-1) \quad \text { for } \quad i=1,2,3, \ldots, N_{x}
$$

where $N_{x}$ is the number of nodes in the $x$ direction and $W$ is the width of the building roof (Figure 1). This equation provides the direction coordinate of the nodes $x$. For the nodes in direction $y$, the coordinate is given by:

$$
y(j)=\frac{y_{1}}{N_{y}-1}(j-1) \quad \text { for } j=1,2,3, \ldots, N_{y}
$$

where $N_{y}$ is the number of nodes in the $y$ direction and $y_{1}$ is the height of the building roof (Figure 1). It is also necessary to know the thickness of the control volume in both directions, and Equation (10) is used to calculate such thicknesses:

$$
\Delta x=\frac{W}{N_{x}-1} \quad \Delta y=\frac{y_{1}}{N_{y}-1}
$$




\subsection{Discretization of the Mathematical Model}

Discretization consists of applying a technique to transform the partial differential equation of the mathematical model into a set of algebraic expressions to facilitate its solution. For the internal nodes, the Equation (1) governs their behavior, and this equation is known as the general differential equation for diffusion processes and can be represented by:

$$
\frac{\partial \rho \phi}{\partial t}=\frac{\partial}{\partial x}\left(\Gamma \frac{\partial \phi}{\partial x}\right)+\frac{\partial}{\partial y}\left(\Gamma \frac{\partial \phi}{\partial y}\right) \text { for } 0<x<W ; 0<y<y_{1}
$$

where: $\phi=T, \Gamma=\lambda / c_{p}$. Taking the domain of interest, for each term of the previous equation, between the points $w$ and $e$ in the $x$ direction of the control volume in Figure 2 and between the points $n$ and $s$ in the $y$ direction and, furthermore, considering the time step, a domain of interest is taken from an earlier time $\left(t_{0}\right)$ to a later time $\left(t=t_{0}+\Delta t\right)$ :

$$
\begin{aligned}
\int_{t_{0}}^{t} \int_{s}^{n} \int_{w}^{e} \frac{\partial \rho \phi}{\partial t} d x d y d t & =\int_{s}^{n} \int_{w}^{e} \frac{\partial}{\partial x}\left(\Gamma \frac{\partial \phi}{\partial x}\right) d x d y+\int_{s}^{n} \int_{w}^{e} \frac{\partial}{\partial y}\left(\Gamma \frac{\partial \phi}{\partial y}\right) d x d y \\
& +\int_{s}^{n} \int_{w}^{e} S d x
\end{aligned}
$$

Integrating in the space the previous equation over the control volume, the following is obtained:

$$
\left[\frac{\partial \overline{\rho \phi}}{\partial t}\right] \Delta x \Delta y=\left[\left(\Gamma \frac{\partial \phi}{\partial x}\right)_{e}-\left(\Gamma \frac{\partial \phi}{\partial x}\right)_{w}\right] \Delta y+\left[\left(\Gamma \frac{\partial \phi}{\partial y}\right)_{n}-\left(\Gamma \frac{\partial \phi}{\partial y}\right)_{s}\right] \Delta x+\bar{S} \Delta x \Delta y
$$

Now, using an implicit interpolation scheme for time:

$$
\begin{aligned}
{\left[\frac{(\rho \phi)_{P}^{t}-(\rho \phi)_{P}^{t_{0}}}{\Delta t}\right] \Delta x \Delta y } & =\left[\left(\Gamma \frac{\partial \phi}{\partial x}\right)_{e}^{t}-\left(\Gamma \frac{\partial \phi}{\partial x}\right)_{w}^{t}\right] \Delta y+\left[\left(\Gamma \frac{\partial \phi}{\partial y}\right)_{n}^{t}-\left(\Gamma \frac{\partial \phi}{\partial y}\right)_{s}^{t}\right] \Delta x \\
& +\bar{S} \Delta x \Delta y
\end{aligned}
$$

Because the conditions at the interfaces were unknown and the centered scheme interpolation was used, using the known values of the nodes adjacent to that control volume interface (nodes $\mathrm{E}, \mathrm{W}, \mathrm{N}$, and S), the following was obtained:

$$
\begin{aligned}
{\left[\frac{(\rho \phi)_{P}^{t}-(\rho \phi)_{P}^{t_{0}}}{\Delta t}\right] \Delta x \Delta y } & =\Gamma_{e}\left(\frac{\phi_{E}-\phi_{P}}{\delta x_{P E}}\right) \Delta y-\left(\frac{\phi_{P}-\phi_{W}}{\delta x_{P W}}\right) \Delta y+\Gamma_{n}\left(\frac{\phi_{N}-\phi_{P}}{\delta y_{P N}}\right) \Delta x \\
& -\Gamma_{S}\left(\frac{\phi_{P}-\phi_{S}}{\delta y_{P S}}\right) \Delta x+\bar{S} \Delta x \Delta y
\end{aligned}
$$

It is convenient to group the terms of the equation into coefficients as follows:

$$
\begin{gathered}
\phi_{P} \underbrace{\left[\left(\frac{\rho \Delta x \Delta y}{\Delta t}\right)+\left(\frac{\Gamma_{e}}{\delta x_{P E}}+\frac{\Gamma_{w}}{\delta x_{P W}}\right) \Delta y+\left(\frac{\Gamma_{n}}{\delta y_{P N}}+\frac{\Gamma_{S}}{\delta y_{P S}}\right) \Delta x\right]}_{a_{P}}=\phi_{E} \underbrace{\left(\frac{\Gamma_{e} \Delta y}{\delta x_{P E}}\right)}_{a_{E}} \\
+\phi_{W} \underbrace{\left(\frac{\Gamma_{w} \Delta y}{\delta x_{P W}}\right)}_{a_{W}}+\phi_{N} \underbrace{\left(\frac{\Gamma_{n} \Delta x}{\delta y_{P N}}\right)}_{a_{N}}+\phi_{S} \underbrace{\left(\frac{\Gamma_{S} \Delta x}{\delta x_{P S}}\right)}_{a_{S}}+\phi_{P}^{t_{0}} \underbrace{\left(\frac{\rho \Delta x \Delta y}{\Delta t}\right)^{t_{0}}}_{a_{P}^{0}}+\bar{S} \Delta x \Delta y
\end{gathered}
$$


Therefore:

$$
\begin{gathered}
a_{E}=\frac{\Gamma_{e} \Delta y}{\delta x_{P E}} \quad a_{W}=\frac{\Gamma_{w} \Delta y}{\delta x_{P W}} \quad a_{N}=\frac{\Gamma_{n} \Delta x}{\delta y_{P N}} \quad a_{S}=\frac{\Gamma_{s} \Delta x}{\delta x_{P S}} \\
a_{P}^{0}=\frac{\rho \Delta x \Delta y}{\Delta t} \\
b=S \Delta x \Delta y+a_{P}^{0} \phi_{P}^{0} \\
a_{P}=a_{E}+a_{W}+a_{N}+a_{S}+a_{P}^{0}-\bar{S} \Delta x \Delta y
\end{gathered}
$$

We obtain here Equation (11), which is the generative equation of the system of algebraic equations in the notation of grouped coefficients:

$$
a_{P} \phi_{P}=a_{E} \phi_{E}+a_{W} \phi_{W}+a_{N} \phi_{N}+a_{S} \phi_{S}+b
$$

It is also necessary to discretize the boundary nodes. According to the physical model, there is a third class condition (interior surface of the roof), two second class conditions at the left and right ends, and another third class with radiative loss or gain in the exterior surface.

\subsection{Solution of the System of Algebraic Equations}

If the system of algebraic equations resulting from the discretization of a two-dimensional model is adjusted in a matrix way, a matrix of pentagonal and diagonally dominant coefficients is obtained. For the one-dimensional case, the Thomas algorithm or tridiagonal matrix algorithm (TDMA) is applied as a direct method by the dominant tridiagonal matrix of coefficients; however, Thomas's algorithm can be used for the two-dimensional case by combining it with iterative equation solving methods. In this work, the system of algebraic equations was solved using the line-by-line Gauss-Seidel method with alternating directions (LGS-ADI).

\section{Verification and Validation of the Mathematical Model}

The mathematical model as mentioned above was solved using the finite volume method; thus, it was necessary to develop a computer simulation tool that could follow the solution methodology described in Section 4. The numerical code was developed in the Fortran programming language. First, the mathematical model was used to solve a reference exercise available in the literature to verify that it was able to provide reliable results. It was verified by comparing its results against the analytical solution for a composite solid reported by Chen and Paine [21]. Then, the mathematical model was subjected to another test known as validation, where the results of the model were compared with data from temperature measurements from a roof under outdoor ambient conditions. To validate the numerical model that solved the heat conduction equation, experimental data from a previous publication of the author were used [22]. The model was validated for two cases: a conventional gray roof and a white reflective roof. In the experiment performed by Hernández-Pérez et al. [22] with two test cells, the exterior surface temperature of the roofs was measured every $10 \mathrm{~min}$ for five days. Figure 3 shows the temperatures obtained by solving the model and the experimental temperatures. This figure shows that the model satisfactorily reproduced the behavior of the gray roof and the white reflective roof. The maximum deviations of the temperatures obtained for the gray and white roofs were $5.5 \%$ and $4.6 \%$, respectively. Therefore, this model can be used to study the thermal performance of concrete roof slabs in different weather conditions. One advantage that the current model brought is that most of the validated tools available were validated for a single day $[17,23]$. In contrast, the model presented by the author was validated by using data 
from an experimental test performed for five consecutive days. In other words, this tool was validated by comparing its results with 720 temperature values for each type of roof.

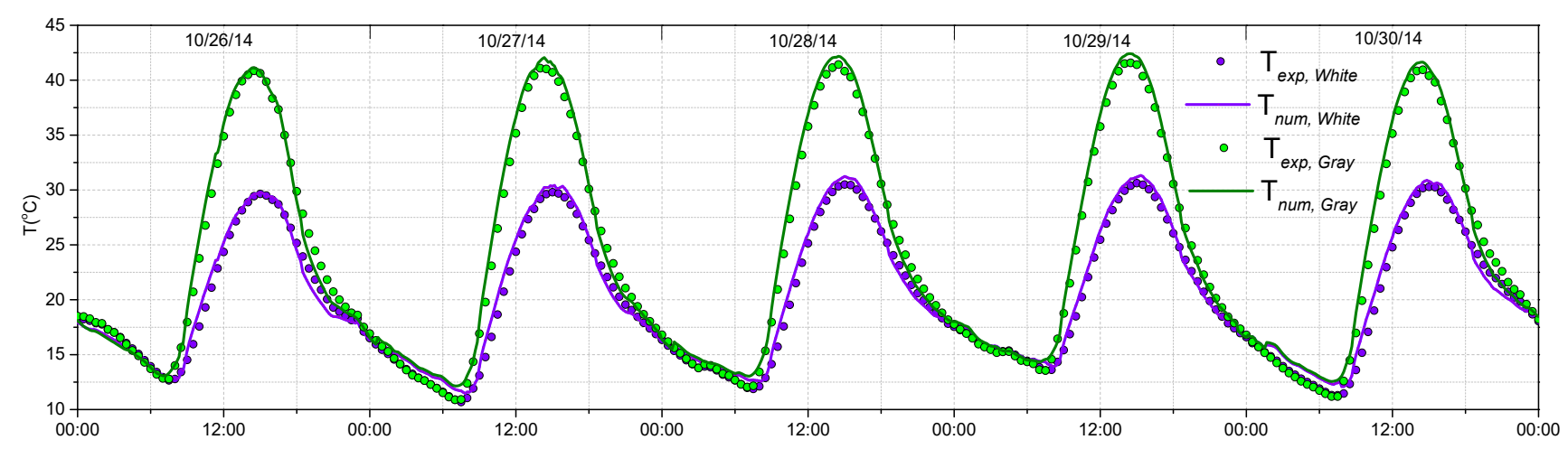

Figure 3. Comparison of the experimental data from Hernández-Pérez et al. [22] and the data obtained with the numerical model.

\section{Weather Data}

Once the roof model was verified and validated, its thermal behavior was studied under the outdoor environment of different cities. Data from four representative towns in Mexico with warm weather were used. Table 1 shows the four major cities with their corresponding type of weather. The weather data used for the simulations were filtered from files provided by the National Meteorological Service-National Commission of Water (Servicio Meteorológico Nacional-Comisión Nacional del Agua (SMN-CONAGUA)), the public body responsible for providing information on the state of the weather that prevails or affects the territory of this country. The SMN-CONAGUA obtains the weather data files from weather stations situated in each city. The data files contained recorded several variables recorded every ten minutes for a whole year. Still, only solar radiation, wind speed, and air temperature for the simulations were used, as shown in the Results Section. The thermal behavior of the roofs was analyzed for the week with the highest temperatures of the year 2018.

Table 1. Representative cities of the zones with warm weather in Mexico.

\begin{tabular}{cc}
\hline City & Weather Type \\
\hline Hermosillo, Sonora & Warm dry \\
Monterrey, N.L. & Warm semi-dry \\
Villahermosa, Tabasco & Warm humid \\
Mérida, Yucatán & Warm semi-humid \\
\hline
\end{tabular}

\section{Properties of Traditional and Reflective Coatings}

Table 2 shows the values of solar absorptance and thermal emittance of the four coatings analyzed in this research. There were two traditional coatings, gray and terracotta, and two solar reflective coatings, White \# 1 and White \# 2 . These optical properties of the coatings were measured in two previous works of the author [12,22]. The solar reflectance was measured using a spectrophotometer with an integrating sphere following the procedure indicated in the standard ASTM E 903-12. After obtaining the solar reflectance, the solar absorptance was calculated because this property was required in the boundary conditions of the model as presented above. A portable ambient temperature emissometer was used, according to the standard ASTM C1371 (2015): laboratory or field measurement of hemispherical thermal emittance with a portable emissometer (indirect technique using calibrated references) the thermal emittance obtained for all coating samples obtained at ambient temperature. The emittance of the coatings can be considered a constant value independent of temperature because the coatings were opaque materials that could be 
considered as paint, and according to Duffie and Beckman [19], the emittance of these materials only changed slightly at very high temperatures.

Table 2. Optical properties of the coatings.

\begin{tabular}{ccc}
\hline Coating & Solar Absorptance $(\boldsymbol{\alpha})$ & Thermal Emittance $(\varepsilon)$ \\
\hline Gray & 0.67 & 0.87 \\
Terracotta & 0.70 & 0.88 \\
White \# 1 & 0.20 & 0.90 \\
White \# 2 & 0.16 & 0.89 \\
\hline
\end{tabular}

\section{Results}

This section presents the concrete roof's behavior with four coatings in terms of the temperature of the exterior surface, the temperature of the interior surface, and the heat flux traveling through the roofs. Further, the cumulative heat gain was obtained by determining the area under the heat flux curve for each day. This section shows first the results for the single roof configuration and then the corresponding results for the insulated roof configuration.

\subsection{Single Roof}

As mentioned above, the roofs' thermal behavior was analyzed using the weather data of the week with the warmest outdoor air temperatures of 2018 using weather data from four representative towns in Mexico with a warm climate. The detailed results of Hermosillo are shown here because it was the town with the highest outdoor temperature. At the end of this subsection, a summary table presents the results of the thermal evaluation of the single roof in all cities.

For Hermosillo Sonora, the days selected were from 30 May to 5 June 2018 because this was the week with the highest temperatures of the year. Figure 4a shows the solar irradiation and the wind speed during the seven days analyzed. The maximum solar radiation was around $1000 \mathrm{~W} / \mathrm{m}^{2}$. According to the behavior of solar irradiance, all days selected were clear days without clouds. The maximum wind speed reached around $5 \mathrm{~m} / \mathrm{s}$. Figure $4 \mathrm{~b}$ shows the air temperature; due to the type of weather of this city, the ambient air reached very high temperatures, with an average maximum temperature of $45^{\circ} \mathrm{C}$.

Figure $4 \mathrm{~b}$ presents the temperature of the exterior surface of the roofs and the ambient air temperature during the selected week. Conventional roofs had a similar behavior, and on the other hand, reflective roofs maintained a similar behavior concerning the temperature of the exterior surface. This effect occurred because the solar reflectance of conventional coatings was very similar. The exterior surface of the roofs reached its maximum temperature between 14:30 and 15:00 $\mathrm{h}$. The exterior surface of the single terracotta roof (STR), the single gray roof (SGR), Single White Roof \#1 (SWR1), and Single White Roof \#2 (SWR2) reached on average $61,59,45$, and $43{ }^{\circ} \mathrm{C}$, respectively. These values indicated that applying the terracotta coating, on average, increased the temperature of the exterior surface by $2{ }^{\circ} \mathrm{C}$ compared to the SGR. In contrast, SWR1 and SWR2 reduced the temperature of the exterior surface by on average 14 and $16^{\circ} \mathrm{C}$, respectively. Furthermore, if the average maximum temperatures of reflective roofs were compared with the average maximum temperature of ambient air $\left(45^{\circ} \mathrm{C}\right)$, SWR1 had the same maximum temperature as the ambient air. In contrast, SWR2 reached a temperature of $2{ }^{\circ} \mathrm{C}$ lower than the maximum air temperature. On the other hand, the SGR and STR reached a temperature of 14 and $16^{\circ} \mathrm{C}$ higher than the ambient air temperature. 
(a)

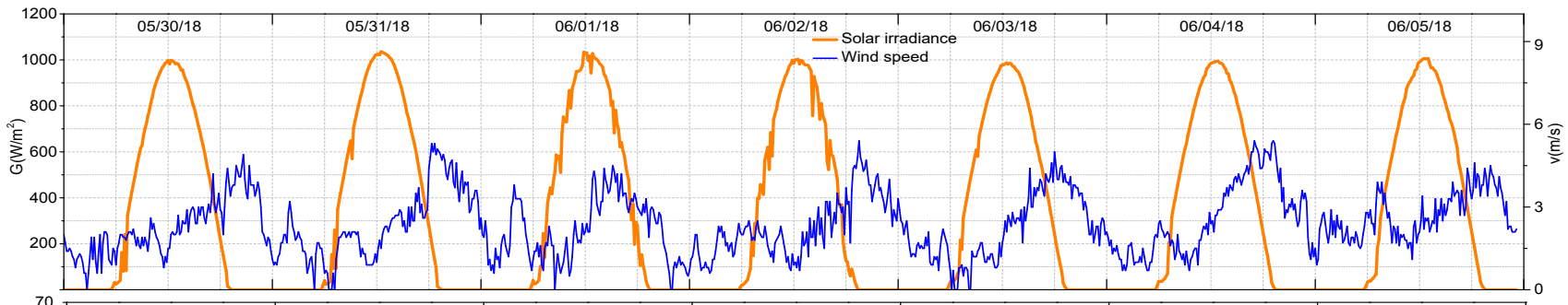

(b)

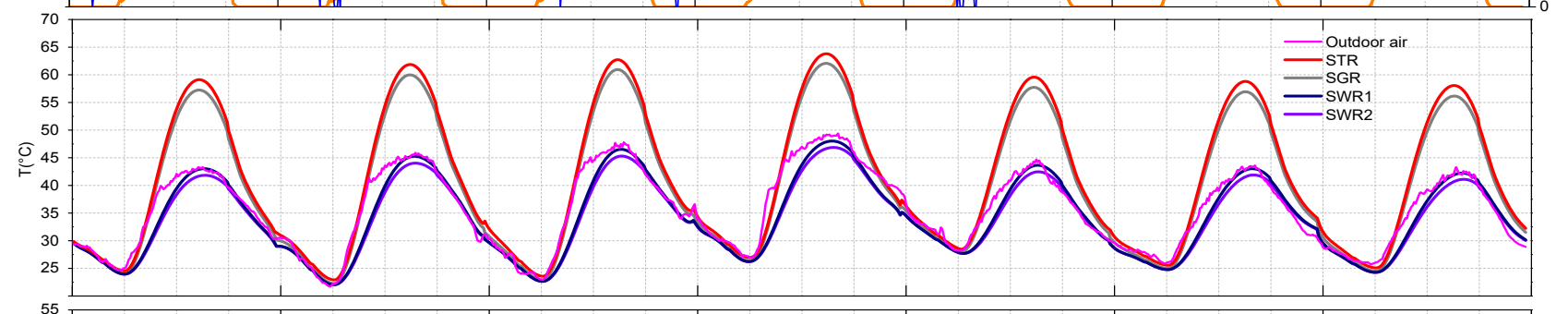

(c)

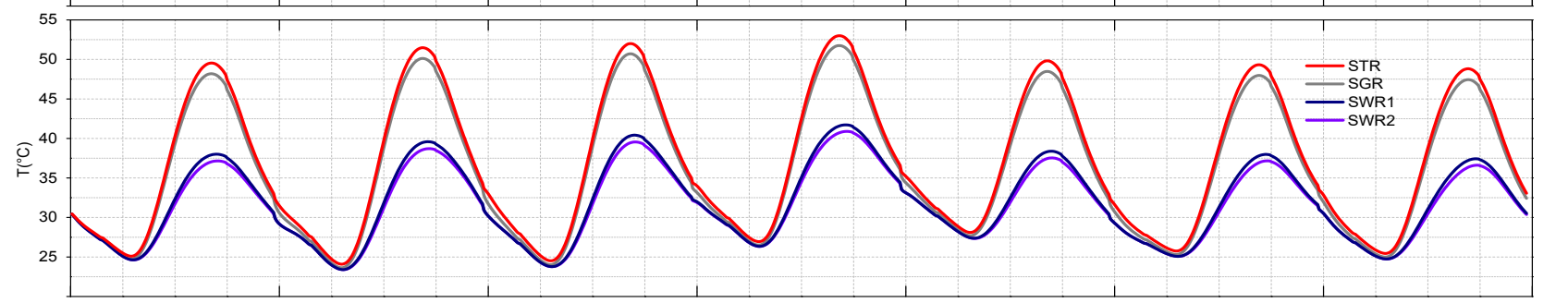

(d)

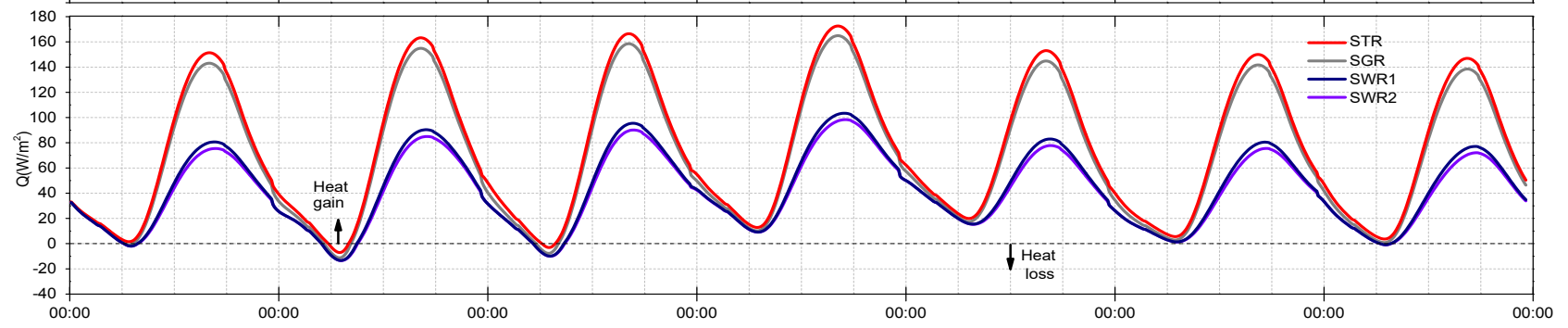

Figure 4. Thermal behavior of the single roof with traditional and solar reflective coatings in Hermosillo: (a) solar irradiance and wind speed; (b) temperature of exterior surface and outdoor air; (c) temperature of interior surface; (d) heat flux of the roofs.

Figure $4 \mathrm{c}$ presents the temperature of the single roofs' interior surface. The interior surface of the roofs reached their maximum temperature between 16:00 and 16:40 $\mathrm{h}$. The temperature of the interior surface of the STR, SGR, SWR1, and SWR2 reached a maximum temperature of $51,49,38$, and $37^{\circ} \mathrm{C}$, respectively. Therefore, the influence of a reflective coating on the interior surface temperature was obtained by comparing the previous temperature values. SWR1 decreased the temperature of the interior surface by around $10^{\circ} \mathrm{C}$ compared to the SGR, while SWR2 reduced the temperature of this surface by around $11^{\circ} \mathrm{C}$.

Figure $4 \mathrm{~d}$ shows the behavior of the heat flux of the roofs in Hermosillo during the seven days analyzed. The maximum heat flux traveling through the roofs occurred between 16:00 and 16:50 $\mathrm{h}$. The STR, SGR, SWR1, and SWR2 had an average peak heat flux of $157,150,87$, and $82 \mathrm{~W} / \mathrm{m}^{2}$, respectively. These values indicated that the peak heat flux crossing SWR1 and SWR2 was $41 \%$ and $45 \%$ smaller than that corresponding to the SGR, while the heat flux of the STR was 5\% greater than that of the SGR. The cumulative heat gain for one day or daily heat gain was obtained by calculating the area under the heat flux curve for each day. During the seven days analyzed, the STR had an average heat gain of $1793 \mathrm{~W} \cdot \mathrm{h} /\left(\mathrm{m}^{2}\right.$-day), the SGR a gain of $1675 \mathrm{~W} \cdot \mathrm{h} /\left(\mathrm{m}^{2}\right.$-day $)$, the SWR1 of $1045 \mathrm{~W} \cdot \mathrm{h} /\left(\mathrm{m}^{2}\right.$-day), and the SWR2 roof of $993 \mathrm{~W} \cdot \mathrm{h} /\left(\mathrm{m}^{2}\right.$-day). Thus, by calculating the percentage difference between the average daily heat gain, it was found that the TSR 
located in Hermosillo had a 7\% greater heat gain than the SGR, while the SWR1 and SWR2 roofs had 38 and $41 \%$ less heat gain than the gray roof.

A similar procedure for the other three cities was developed to perform the simulations; the week with the warmest outdoor air temperatures of 2018 was selected. The weather data from this week were introduced to the simulation tool. Table 3 presents a summary of the results obtained from the evaluation of the single roof with traditional and solar reflective coatings in the four cities of Mexico. The table shows the average peak surface temperatures $\left(T_{e s}\right.$ and $\left.T_{i s}\right)$, the average peak heat flux $\left(Q_{R}\right)$, and the average daily heat gain of the roofs $(H G)$. Taking the SGR as a reference, the percentage differences between the peak heat flux of this roof and the other cases are also given within parenthesis (\%) in the table, and the same is done for the heat gain. Table 3 demonstrates that SWR1 and SWR2 were able to reduce $T_{e s}$ between 11 and $16{ }^{\circ} \mathrm{C}$ compared to the gray roof. Thus, the peak heat flux crossing the SGR can be shaved between 42 and $57 \%$ due to a white reflective coating application. Further, SWR1 and SWR2 reduced $H G$ between 41 and $85 \%$. On the other hand, the STR reached a maximum temperature $2{ }^{\circ} \mathrm{C}$ above the SGR temperature in all cities. These higher temperatures caused an increase in the daily heat gain between 7 and $11 \%$.

Table 3. Summary of the thermal evaluation of a single roof in four cities of Mexico (Average peak values for the different variables).

\begin{tabular}{cccccc}
\hline City & Roof & $T_{e s}\left({ }^{\circ} \mathbf{C}\right)$ & $T_{i s}\left({ }^{\circ} \mathbf{C}\right)$ & $Q_{R}\left(\frac{\mathbf{W}}{\mathbf{m}^{2}}\right)$ & $H G\left(\frac{\mathbf{W} \cdot \mathbf{h}}{\mathbf{m}^{2}-\text { day }}\right)$ \\
\hline \multirow{5}{*}{ Monterrey } & SGR & 51 & 43 & 113 & 1109 \\
& SWR1 & 38 & 34 & $56(-50 \%)$ & $563(-49 \%)$ \\
& SWR2 & 37 & 33 & $52(-54 \%)$ & $520(-53 \%)$ \\
& STR & 53 & 45 & $121(+7 \%)$ & $1213(+9 \%)$ \\
\hline \multirow{5}{*}{ Hermosillo } & SGR & 59 & 49 & 150 & 1675 \\
& SWR1 & 45 & 39 & $87(-42 \%)$ & $1045(-38 \%)$ \\
& SWR2 & 43 & 38 & $82(-45 \%)$ & $993(-41 \%)$ \\
& STR & 61 & 51 & $157(+5 \%)$ & $1793(+7 \%)$ \\
\hline \multirow{5}{*}{ Villahermosa } & SGR & 50 & 43 & 111 & 1097 \\
& SWR1 & 37 & 34 & $53(-52 \%)$ & $550(-50 \%)$ \\
& SWR2 & 36 & 33 & $48(-57 \%)$ & $506(-54 \%)$ \\
& STR & 52 & 44 & $120(+8 \%)$ & $1219(+11 \%)$ \\
\hline \multirow{5}{*}{ Mérida } & SGR & 53 & 43 & 123 & 1148 \\
& SWR1 & 39 & 34 & $61(-50 \%)$ & $569(-50 \%)$ \\
& SWR2 & 38 & 33 & $56(-54 \%)$ & $511(-54 \%)$ \\
& STR & 55 & 44 & $131(+7 \%)$ & $1255(+9 \%)$ \\
\hline
\end{tabular}

\subsection{Insulated Roof}

The insulated roof was studied also in Hermosillo as it was the warmest city among the selected locations. As in the previous section, first, the detailed analysis of this city is presented, and then, the results for other cities are summarized at the end of this subsection.

Figure $5 \mathrm{~b}$ shows the behavior of the temperature of the external surface of the insulated roofs and the temperature of the ambient air during the seven days considered. Insulated roofs with a conventional color had a similar behavior, and on the other hand, the insulated roofs with reflective coating maintained a similar behavior regarding the temperature of the exterior surface. The exterior surface of the roofs reached its maximum temperature between 13:30 and 14:00 $\mathrm{h}$. The exterior surface of the insulated terracotta roof (ITR) reached on average $72{ }^{\circ} \mathrm{C}$, the insulated gray roof (IGR) 69 $9^{\circ}$, Insulated White Roof \#1 (IWR1) $50{ }^{\circ} \mathrm{C}$, and Insulated White Roof \#2 (IWR2) $49^{\circ} \mathrm{C}$. These temperatures indicated that ITR had on average a temperature of the exterior surface about $3^{\circ} \mathrm{C}$ higher than the IGR, while IWR1 and IWR2 reduced the temperature of the exterior surface by 19 and $20^{\circ} \mathrm{C}$ on average, respectively. If the average maximum temperatures of white reflective roofs were compared with the average maximum temperature of ambient air $\left(45^{\circ} \mathrm{C}\right)$, IWR1 
had a maximum temperature of $5{ }^{\circ} \mathrm{C}$ above the maximum air temperature, while the IWR2 roof reached a temperature $4^{\circ} \mathrm{C}$ higher than the maximum air temperature. On the other hand, the IGR and ITR reached a temperature of 23 and $26^{\circ} \mathrm{C}$ higher than the maximum ambient air temperature, respectively.

(a)
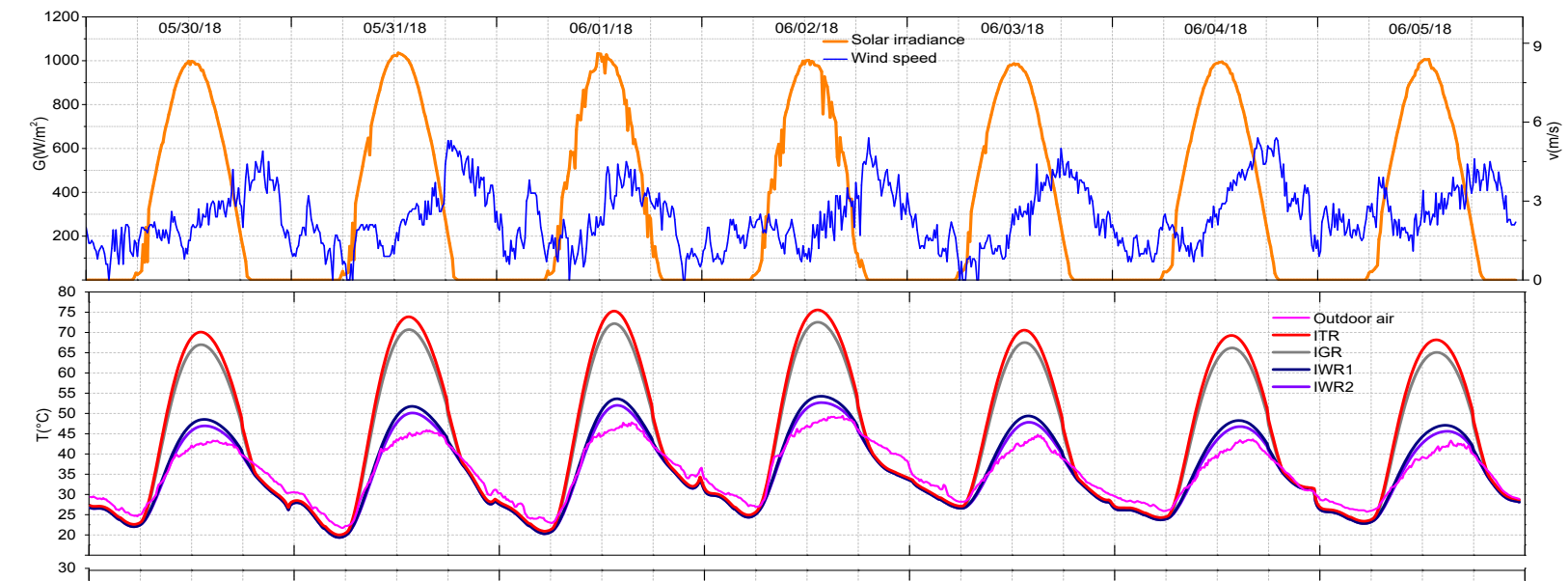

(b)

(c)
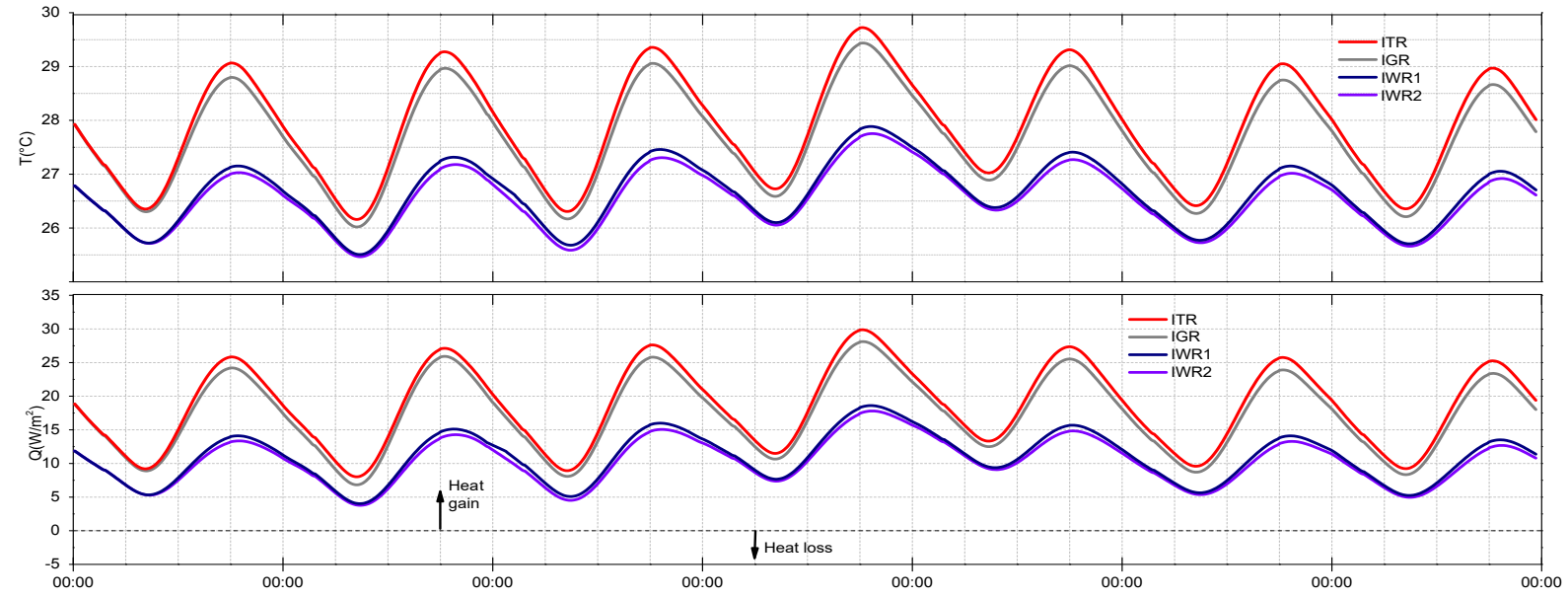

Figure 5. Thermal behavior of the insulated roof with traditional and reflective coatings in Hermosillo: (a) solar irradiance and wind speed; (b) temperature of exterior surface and outdoor air; (c) temperature of interior surface; (d) heat flux of the roofs.

Figure $5 \mathrm{c}$ shows the temperature of the interior surface of the four roofs. Due to thermal insulation, the temperatures of the roofs' interior surface had a small oscillation between day and night compared to the cases without insulation. These surfaces reached their maximum temperature between 17:30 and 18:10 h. The temperature of the interior surface of the ITR and that of the IGR reached a maximum temperature of $29.3^{\circ} \mathrm{C}$ and $29^{\circ} \mathrm{C}$, while the surface temperature of IWR1 and IWR2 reached $27.4^{\circ} \mathrm{C}$ and $27.2^{\circ} \mathrm{C}$. This figure demonstrates that the insulation caused the interior temperature of the roofs to remain relatively constant.

Figure $5 \mathrm{~d}$ shows the behavior of the heat flux of the insulated roofs in Hermosillo. The maximum heat flux traveling through the roofs occurred between 17:30 and 18:10 $\mathrm{h}$. Insulated traditional roofs (ITR and IGR) had an average peak heat flux of 27 and $25.3 \mathrm{~W} / \mathrm{m}^{2}$, while insulated white reflective roofs, IWR1 and IWR2, had a peak heat flux of 15.4 and $14.6 \mathrm{~W} / \mathrm{m}^{2}$. As mentioned above, the total heat gain of the roof over a day was determined by calculating the area under the heat flux curve of each day. The ITR had an average heat gain of $304 \mathrm{~W} \cdot \mathrm{h} /\left(\mathrm{m}^{2}\right.$-day), the IGR of $273 \mathrm{~W} \cdot \mathrm{h} /\left(\mathrm{m}^{2}\right.$-day), IWR2 of $140 \mathrm{~W} \cdot \mathrm{h} /\left(\mathrm{m}^{2}\right.$-day $)$, and IWR2 of $128 \mathrm{~W} \cdot \mathrm{h} /\left(\mathrm{m}^{2}\right.$-day). The ITR located in Hermosillo had a $6 \%$ higher heat gain than the IGR, while IWR1 and IWR2 had a 37 and 40\% lower heat gain than the IGR.

Finally, the insulated roofs' thermal behavior was simulated for the remaining cities following the same procedure used for Hermosillo. Table 4 presents a summary of the 
results obtained from the evaluation of the insulated roofs in the four cities of Mexico. The table shows the values for the average peak temperature of the exterior $\left(T_{e s}\right)$ and the interior surface $\left(T_{i s}\right)$, the average peak heat flux of the roofs $\left(Q_{R}\right)$, and the average daily heat gain $(H G)$. Taking the IGR as the control case, the differences between the peak temperatures $\left(T_{e S}\right.$ and $\left.T_{i s}\right)$ were calculated, along with the peak heat flux $\left(Q_{R}\right)$ and the heat gain $(H G)$. The white reflective roofs were able to reduce $T_{e s}$ between 17 and $21^{\circ} \mathrm{C}$ compared to the IGR. Therefore, they could reduce the $Q_{R}$ that crossed the roofs by a factor ranging between 39 and 54\%. Further, these roofs had an HG between 37 and 56\% smaller than the ISG. On the other hand, the ITR reached a maximum temperature of $3{ }^{\circ} \mathrm{C}$ above the IGR. This temperature increment caused an increase of the $Q_{R}$ between $7 \%$ and $15 \%$. Moreover, the ITR increased the HG by about 11 and $33 \%$.

Table 4. Summary of the thermal evaluation of insulated roof in four cities of Mexico (Average peak values for the different variables).

\begin{tabular}{cccccc}
\hline City & Roof & $\boldsymbol{T}_{\boldsymbol{e s}}\left({ }^{\circ} \mathbf{C}\right)$ & $\boldsymbol{T}_{\text {is }}\left({ }^{\circ} \mathbf{C}\right)$ & $Q_{R}\left(\frac{\mathbf{W}}{\mathbf{m}^{2}}\right)$ & $\boldsymbol{H G}\left(\frac{\mathbf{W} \cdot \mathbf{h}}{\mathbf{m}^{2}-\text { day }}\right)$ \\
\hline \multirow{5}{*}{ Monterrey } & IGR & 60 & 27.7 & 17.1 & 260 \\
& IWR1 & 43 & 26.3 & $9(-47 \%)$ & $128(-51 \%)$ \\
& IWR2 & 42 & 26.2 & $8(-53 \%)$ & $117(-55 \%)$ \\
& ITR & 63 & 28 & $19(+12 \%)$ & $291(+12 \%)$ \\
\hline \multirow{5}{*}{ Hermosillo } & IGR & 69 & 29 & 25 & 439 \\
& IWR1 & 50 & 27.4 & $15.4(-39 \%)$ & $276(-37 \%)$ \\
& IWR2 & 49 & 27.2 & $14.6(-42 \%)$ & $262(-40 \%)$ \\
& ITR & 72 & 29.3 & $27(+7 \%)$ & $459(+6 \%)$ \\
\hline \multirow{5}{*}{ Villahermosa } & IGR & 58 & 27.7 & 13 & 273 \\
& IWR1 & 41 & 26.3 & $7(-46 \%)$ & $140(-49 \%)$ \\
& IWR2 & 40 & 26.1 & $6(-54 \%)$ & $128(-53 \%)$ \\
& ITR & 61 & 28 & $15(+15 \%)$ & $304(+11 \%)$ \\
\hline \multirow{6}{*}{ Mérida } & IGR & 63 & 27.9 & 19 & 284 \\
& IWR1 & 44 & 26.4 & $10(-47 \%)$ & $139(-51 \%)$ \\
& IWR2 & 42 & 26.2 & $9(-53 \%)$ & $126(-56 \%)$ \\
& ITR & 66 & 28.2 & $21(+11 \%)$ & $318(+12 \%)$ \\
\hline
\end{tabular}

\section{Discussion}

This section discusses the comparison of some of the results obtained in this work with other research available in the literature. Alqalaf and Alawadhi [23] evaluated the thermal effectiveness of a white reflective coating on the exterior surface of a concrete roof in Kuwait. The authors of the previous research built a test cell to perform a series of experiments and then developed a numerical model validated with experimental data. They simulated white and gray roof thermal performance in the season with the highest solar radiation and outdoor air temperature. The results showed that the temperature of the interior surface of the white roof was $6^{\circ} \mathrm{C}$ lower than the temperature of the gray roof. Further, the white roof caused a reduction of the heat flux of 50\%. Because Kuwait's climate is warm and dry, such as the climate of Hermosillo, it is worth comparing the results of the current research with those obtained in [23]. Besides the type of climate, the indoor air temperature and the roofs' thermophysical properties studied in the previous research were very similar to the values used in this work. Table 3 indicates that the temperature of the interior surface of SWR 1 was $10^{\circ} \mathrm{C}$ lower than the temperature of the SGR. At the same time, the heat flux of SWR1 was $42 \%$ smaller than the corresponding to the SGR. Here, we mention only SWR1 because this roof had the same absorptance $(\alpha=0.2)$ as the white roof studied in [23]. However, the solar absorptance of the gray roof analyzed by Alqalaf and Alawadhi $(\alpha=0.8)$ was greater than the absorptance of the SGR considered here $(\alpha=0.67)$. Therefore, this main factor for the reduction of the heat flux presented in [23] was more significant than the reduction of the heat flux presented in the current research. On the other hand, as can be noticed above, the temperature reduction presented 
by [23] was smaller, but this difference occurred because the thickness of the roof analyzed in Alqalaf and Alawadhi was $0.15 \mathrm{~m}$, which was greater than the thickness of the single roof; therefore, the thermal inertia of the roofs was the other factor that caused the slightly different results. Thus, the information presented above demonstrated that the findings of this research work were consistent with what other researchers have reported.

Another contribution of this research that is important to discuss is the influence of thermal insulation on the roofs' thermal performance. This effect can be obtained by comparing the results presented in Tables 3 and 4. Because the thermal insulation caused the roofs to have an indoor surface temperature with small oscillations, the heat flux crossing the insulated roof was very small compared to the flux of single roofs. Thus, the $H G$ of the insulated roofs was around four-times smaller than that corresponding to single roofs regardless of the coating and the city. For instance, using the results for Hermosillo, by comparing the $H G$ of the SGR with the $H G$ of the IGR, it can be noticed that the first value was 3.8-times greater than the second value. Therefore, thermal insulation could have an essential contribution in reducing heat gains. On the other hand, another action that the results of this research can evaluate is the comparison between the SGR and IWR2; this is the comparison of the traditional roof configuration (SGR) with the roof configuration with two retrofitting techniques (thermal insulation and reflective coating). Using again Hermosillo as an example, the HG of SWR was equal to $1675 \mathrm{~W} \cdot \mathrm{h} /\left(\mathrm{m}^{2}\right.$-day) (Table 3), and the $H G$ of IWR2 was equal to $262 \mathrm{~W} \cdot \mathrm{h} /\left(\mathrm{m}^{2}\right.$-day) (Table 4$)$. Comparing the two previous values indicated that a roof with thermal insulation and a solar reflective coating could have a daily heat gain up to 6.4-times smaller than a gray roof without insulation. This result is important; however, thermal insulation installation could be more complex and more expensive than applying a reflective coating. Thus, a life cycle cost analysis is needed to find the more cost-effective configuration of roofs.

\section{Conclusions}

A computational tool was used to simulate the thermal behavior of insulated and non-insulated concrete slab roofs with traditional and solar reflective coatings in four cities with warm climates in Mexico. This simulation tool is a computer model based on the finite volume method that numerically solves the heat conduction equation in an unsteady state. The simulations were done using the weather data for the week with the highest outdoor air temperature. Two traditional and two solar reflective coatings installed on the exterior surface of the roofs were considered, and the following was concluded:

Regarding the simulation of the single roofs, SWR2 was the best configuration to minimize the heat transfer. Due to the small solar absorptance of the coating, SWR2 presented a peak exterior surface temperature up to $16^{\circ} \mathrm{C}$ lower than the temperature of the SGR. Further, the peak interior surface temperature of SWR2 was up to $11^{\circ} \mathrm{C}$ lower than the SGR. Thus, SWR2 diminished the heat flux and the daily heat gains up to $57 \%$ and $54 \%$, respectively.

The insulated roofs simulations indicated that the surface temperature reduction of the exterior surface due to the reflective coatings was more significant than the single roofs. IWR2 was the configuration with the best thermal performance. The maximum temperature reduction provided by IWR2 was $19^{\circ} \mathrm{C}$ lower than the temperature of the IGR. IWR2 provided a maximum interior surface temperature reduction $1.6^{\circ} \mathrm{C}$, which was very small. This effect occurred because the thermal insulation maintained the interior surface with small oscillations. IWR2 reduced the peak heat flux and the daily heat gain up to $54 \%$ and $15 \%$, respectively.

This research highlights the importance of selecting the type of coating to be used in building roofs well. In the terracotta coating, this color had a solar absorptance equal to 0.7 , which was just a little higher than the absorptance of the gray color of bare concrete $(\alpha=0.67)$. The difference in the solar absorptance for these two roofs may seem insignificant, but as shown in the Results Section, the STR had a daily heat gain between 9 and $11 \%$ higher than the SGR. Similarly, the ITR had a daily heat gain between 5 and $12 \%$ 
higher than the IGR. These results demonstrated that even a small increment in the solar absorptance could cause a significant increment in the daily heat gain of the roofs.

Because in buildings situated in warm climates, the roof is a source of unwanted heat, applying a coating with a lower absorptance causes a lower amount of energy to be absorbed by the roof's exterior surface. Therefore, the heat traveling through the roof structure is reduced, and then, the roof exhibits better thermal performance. Since Solar Reflective Coating \# 2 was the material with the smallest solar absorptance, this coating improved both the single and insulated roof thermal behavior. Finally, because most buildings in Mexico have bare gray or terracotta roofs, there is a great potential for using reflective coatings as a retrofitting technique in this country. This research demonstrated that white reflective coatings are an excellent alternative to improve the thermal performance of roofs, which could lead to energy savings and mitigating greenhouse gas emissions from buildings.

Funding: This research received no external funding.

Acknowledgments: The author acknowledges CONACYT-Mexico for the support given through the System of National Researchers program (Sistema Nacional de Investigadores, SNI). The author also acknowledges the Servicio Meteorológico Nacional-Comisión Nacional del Agua (SMN-CONAGUA) for providing the weather data used for the simulations. Finally, the author is grateful to Jesús Xamán from CENIDET for the Finite Volume Method course.

Conflicts of Interest: The author declares no conflict of interest.

\section{Abbreviations}

$\begin{array}{ll}\text { FVM } & \text { Finite volume method } \\ \text { IGR } & \text { Insulated gray roof } \\ \text { ITR } & \text { Insulated terracotta roof } \\ \text { IWR1 } & \text { Insulated White Roof \#1 } \\ \text { IWR2 } & \text { Insulated White Roof \#2 } \\ \text { LGS-ADI } & \text { Line-by-line Gauss-Seidel method with alternating directions } \\ \text { SGR } & \text { Single gray roof } \\ \text { STR } & \text { Single terracotta roof } \\ \text { SWR1 } & \text { Single White Roof \#1 } \\ \text { SWR2 } & \text { Single White Roof \#2 } \\ \text { TDMA } & \text { Tridiagonal matrix algorithm }\end{array}$

\section{Nomenclature}

$\begin{array}{ll}a_{p}, a_{e}, a_{w}, a_{n}, a_{s}, b & \text { coefficients of the discretized equation } \\ c_{p} & \text { specific heat, } \mathrm{J} /(\mathrm{kg} \cdot \mathrm{K}) \\ G & \text { solar radiation, } \mathrm{W} / \mathrm{m}^{2} \\ h & \text { heat transfer coefficient, } \mathrm{W} /\left(\mathrm{m}^{2} \cdot \mathrm{K}\right) \\ H G & \text { daily heat gain, } \mathrm{W} \cdot \mathrm{h} /\left(\mathrm{m}^{2}-\text { day }\right) \\ N_{x} & \text { number of nodes in direction } x \\ N_{y} & \text { number of nodes in direction } y \\ Q_{R} & \text { heat flux through the roofs, } \mathrm{W} / \mathrm{m}^{2} \\ t & \text { time, } \mathrm{s} \\ T & \text { temperature, }{ }^{\circ} \mathrm{C} \\ v & \text { wind speed, } \mathrm{m} / \mathrm{s} \\ W & \text { width of the roof, } \mathrm{m} \\ y_{1} & \text { thickness of the roof, } \mathrm{m} \\ x, y & \text { coordinates, } \mathrm{m} \\ \Delta x, \Delta y & \text { grid spacing, } \mathrm{m}\end{array}$




$\begin{array}{ll}\text { Greek } & \text { solar absorptance } \\ \alpha & \text { dependent variable in the general differential equation } \\ \phi & \text { thermal conductivity, } \mathrm{W} /(\mathrm{m} \cdot \mathrm{K}) \\ \lambda & \text { density, } \mathrm{kg} / \mathrm{m}^{3} \\ \rho & \text { Stefan-Boltzmann constant, } \mathrm{kg} /\left(\mathrm{m}^{3}\right) \\ \sigma & \text { thermal emittance } \\ \varepsilon & \text { diffusion coefficient of the generalized differential equation } \\ \Gamma & \\ \text { Subscripts } & \text { exterior surface } \\ \text { es } & \text { indoor } \\ \text { in } & \text { interior surface } \\ \text { is } & \text { outdoor } \\ \text { out } & \text { sky } \\ \text { sky } & \end{array}$

\section{References}

1. International Energy Agency (IEA). 2019 Global Status Report for Buildings and Construction; Global Alliance for Building and Construction; International Energy Agency: Paris, France, 2019.

2. Rajcic, V.; Perkovic, N.; Bedon, C.; Barbalic, J.; Zarnic, R. Thermal and energy-efficiency assessment of hybrid CLT-glass facade elements. Appl. Sci. 2020, 10, 3071. [CrossRef]

3. Wang, Z.; Tian, Q.; Jia, J. Numerical study on performance optimization of an energy-saving insulated window. Sustainability 2021, 13, 935. [CrossRef]

4. Gullbrekken, L.; Grynning, S.; Gaarder, J.E. Thermal performance of insulated constructions—Experimental studies. Buildings 2019, 9, 49. [CrossRef]

5. Saber, H.H.; Hajiah, A.E.; Alshehri, S.A.; Hussain, H.J. Investigating the effect of dust accumulation on the solar reflectivity of coatings materials for cool roofs applications. Energies 2021, 14, 445. [CrossRef]

6. Triano-Juárez, J.; Macias-Melo, E.V.; Hernández-Pérez, I.; Aguilar-Castro, K.M.; Xamán, J. Thermal behavior of a phase change material in a building roof with and without reflective coating in a warm humid zone. J. Build. Eng. 2020, 32, 101648. [CrossRef]

7. Miszczuk, A.; Heim, D. Parametric study of air infiltration in residential buildings-The effect of local conditions on energy demand. Energies 2021, 14, 127. [CrossRef]

8. Hernández-Pérez, I.; Álvarez, G.; Xamán, J.; Zavala-Guillén, I.; Arce, J.; Simá, E. Thermal performance of reflective materials applied to exterior building components. Energy Build. 2014, 80, 81-105. [CrossRef]

9. Todeschi, V.; Mutani, G.; Baima, L.; Nigra, M.; Robiglio, M. Smart solutions for sustainable cities-The re-coding experience for harnessing the potential of urban rooftops. Appl. Sci. 2020, 10, 7112. [CrossRef]

10. Pisello, A.L.; Cotana, F. The thermal effect of an innovative cool roof on residential buildings in Italy: Results from two years of continuous monitoring. Energy Build. 2014, 69, 154-164. [CrossRef]

11. Qin, Y.; He, Y.O.; Wu, B.; Ma, Z.; Zhang, X. Regulating top albedo and bottom emissivity of concrete roof tiles for reducing building heat gains. Energy Build. 2017, 156, 218-224. [CrossRef]

12. Hernández-Pérez, I.; Zavala-Guillén, I.; Xamán, J.; Belman-Flores, J.M.; Macias-Melo, E.V.; Aguilar-Castro, K.M. Test box experiment to assess the impact of waterproofing materials on the energy gain of building roofs in Mexico. Energy 2019, 158, 115847. [CrossRef]

13. Algarni, S. Potential for cooling load reduction in residential buildings using cool roofs in the harsh climate of Saudi Arabia. Energy Environ. 2008, 30, 235-253 [CrossRef]

14. Piselli, C.; Pisello, A.L.; Saffari, M.; de Gracia, A.; Cotana, F.; Cabeza, L.F. Cool roof impact on building energy need: The roleof thermal insulation with varying climate conditions. Energies 2019, 12, 3354. [CrossRef]

15. Dominguez-Delgado, A.; Dominguez-Torres, H.; Dominguez-Torres, C.A. Energy and economic life cycle assessment of cool roofs applied to the refurbishment of social housing in southern Spain. Sustainability 2020, 12, 5602. [CrossRef]

16. Tong, S.; Li, H.; Zingre, K.T.; Wan, M.P.; Chang, V.W.C.; Wong, S.K.; Toh, W.B.T.; Lee, I.Y.L. Thermal performance of concrete-based roofs in tropical climate. Energy Build. 2014, 78, 392-401. [CrossRef]

17. Zingre, K.T.; Wan, M.P.; Tong, S.; Li, H.; Chang, V.W.C.; Wong, S.K.; Toh, W.B.T.; Lee, I.Y.L. Modeling of cool roof heat transfer in tropical climate. Renew. Energy 2016, 75, 210-223. [CrossRef]

18. Hahn, D.W.; Ozisik, M.N. Heat Conduction; John Wiley and Sons: Hoboken, NJ, USA, 2012.

19. Duffie, J.A.; Beckman, W.A. Solar Engineering of Thermal Processes; John Wiley and Sons: Hoboken, NJ, USA, 1980.

20. Han, J.; Lin, L.; Yang, H. Investigation on the thermal performance of different lightweight roofing structures and its effect on space cooling load. Appl. Therm. Eng. 2009, 29, 2491-2499. [CrossRef]

21. Chen, K.C.; Payne, U.J. Analytical solution for heat conduction in a two-material-layer slab with linearly temperature Dependent Conductivity. J. Heat Transfer 1993, 113, 237-239. 
22. Hernández-Pérez, I.; Xamán, J.; Macias-Melo, E.V.; Aguilar-Castro, K.M.; Zavala-Guillén, I.; Hernández-López, I.; Simá, E. Experimental thermal evaluation of building roofs with conventional and reflective coatings. Energy Build. 2018, 158, 569-579. [CrossRef]

23. Alqalaf, H.J.; Alawadhi, E.M. Thermal analysis of a concrete roof with an outdoor reflective surface. J. Energy Eng. 2015, 142, 05015001. [CrossRef] 